\title{
Valor nutritivo e cinética de degradação in vitro de genótipos de capim-elefante (Penissetum purpureum Schumach) sob dois intervalos de desfolhação e duas alturas de resíduo pós-pastejo
}

[Nutritive value and in vitro kinetics degradation of elephant grass genotypes (Penissetum purpureum Schumach) under two intervals of defoliation and two post-grazing heights]

\author{
C.S. Chaves ${ }^{1}$, K.G. Ribeiro ${ }^{2 *}$, C.A.M. Gomide ${ }^{3}$, D.S.C. Paciullo ${ }^{3}$, \\ M.J.F. Morenz ${ }^{3}$, D.S. Gama ${ }^{3}$ \\ ${ }^{1}$ Universidade Federal dos Vales do Jequitinhonha e Mucuri - Diamantina, MG \\ ${ }^{2}$ Universidade Federal de Viçosa - Viçosa, MG \\ ${ }^{3}$ Embrapa Gado de Leite - Juiz de Fora, MG
}

\begin{abstract}
RESUMO
O experimento foi conduzido na Embrapa Gado de Leite, em Coronel Pacheco, MG, com o objetivo de avaliar o valor nutritivo e a cinética de degradação in vitro de genótipos de capim-elefante submetidos ao pastejo, usando-se a técnica de mob-grazing. Utilizou-se a combinação fatorial $(2 \times 2 \times 2)$, sendo dois genótipos de capim-elefante (BRS Kurumi e CNPGL 00-1-3), duas interceptações luminosas (IL) à entrada dos animais nos piquetes $(90$ e $95 \%$ ) e duas alturas de resíduo pós-pastejo (30 e $50 \mathrm{~cm})$, dispostos num delineamento inteiramente ao acaso, com três repetições. Para o pastejo, foram usadas 24 novilhas mestiças Holandês x Zebu, com 190kg. O genótipo BRS Kurumi apresentou maior teor de PB (15,65\%), menor teor de FDN (60,35\%), maior coeficiente de digestibilidade (70,04\%) e mais alta taxa de degradação $\left(2,62 \% \mathrm{~h}^{1}\right)$ em relação ao outro genótipo, quando manejados a $90 \%$ IL. O manejo a $95 \%$ de IL e resíduo de $30 \mathrm{~cm}$ favoreceu mais altos teores de PB (14,04\%) e coeficientes de DIVMS $(69,81 \%)$ e mais baixos teores de FDN (60,61\%), independentemente do genótipo. Assim, recomenda-se a utilização do genótipo Kurumi, manejado a $90 \%$ de IL e resíduo de $30 \mathrm{~cm}$, quando se leva em consideração o valor nutritivo da forragem.
\end{abstract}

Palavras-chave: digestibilidade in vitro da matéria seca, fibra em detergente neutro indigestível, interceptação luminosa, pastejo rotativo, produção de gás, proteína bruta

\begin{abstract}
The experiment was conducted at Embrapa Gado de Leite, Coronel Pacheco, MG, to evaluate the nutritive value and the in vitro kinetics of degradation of elephant grass genotypes under rotational grazing. The treatments consisted of a factorial combination (2x2x2), two genotypes of elephant grass (BRS Kurumi and CNPGL 00-1-3), two light interceptions (LI) at initiation of grazing (90 and 95\%) and two post-grazing heights (30 and $50 \mathrm{~cm}$ ), arranged in a completely randomized design with three replications. Grazing animals were 24 Holstein Zebu crossbred heifers with $190 \mathrm{~kg}$ BW. The genotype BRS Kurumi has a higher CP content (15.65\%), lower NDF content (60.35\%), higher digestibility (70.04\%) and higher rate of degradation $\left(2.62 \% \mathrm{~h}^{-1}\right)$ in relation to CNPGL 00-1-3 when managed under $90 \%$ of LI. The management based on $95 \%$ of LI and 30cm of residual height promote higher CP content (14.04\%) and coefficient of IVDMD (69.81\%), as well as lower NDF content (60.61\%), regardless of genotype. Thus, taking into account the nutritional value of forage, it is recommended to use the genotype BRS Kurumi managed under $90 \%$ of LI and $30 \mathrm{~cm}$ of post-grazing residue.
\end{abstract}

Keywords: crude protein, gas production, indigestible neutral detergent fiber, in vitro digestibility of dry matter, light interceptation, neutral detergent fiber, rotational grazing

Recebido em 9 de fevereiro de 2015

Aceito em 18 de fevereiro de 2016

*Autor para correspondência (corresponding author)

E-mail: karinaribeiro@ufv.br

Apoio financeiro: FAPEMIG/CNPq 


\section{INTRODUÇÃO}

O capim-elefante anão (Penissetum purpureum Schumach) é caracterizado pelo curto comprimento dos entrenós, com isso a planta demora a elevar seu meristema apical, proporcionando maior relação folha/colmo (Silva et al., 2009). O reduzido alongamento do colmo do capim-elefante anão contribui para minimizar a drástica redução do valor nutritivo da forragem com o avanço da maturidade, comum em cultivares de porte alto.

Além da qualidade da forragem produzida, o capim-elefante anão tem demonstrado elevada persistência. Macoon et al. (2002), ao avaliarem os efeitos da desfolhação sobre a produtividade e persistência de quatro genótipos de Pennisetum, observaram maior sobrevivência do capimelefante anão, e, quando este foi comparado com um híbrido interespecífico de capim-elefante com milheto, o cv. Anão apresentou densidade populacional de perfilhos aproximadamente duas vezes maior.

Em plantas forrageiras, o aumento da idade da planta normalmente é acompanhado pela elevação da porcentagem de matéria seca e da redução da digestibilidade e do valor nutritivo (Van Soest, 1965). Assim, a idade considerada adequada para utilização de uma planta forrageira, ou seja, o momento em que as características de importância forrageira, tais como digestibilidade e teor de MS, proteína bruta e minerais, encontram-se no ponto mais favorável para consumo, pode variar entre espécies e cultivares, em razão dos efeitos genéticos, ambientais e da interação desses fatores (Pereira et al., 2000), além do manejo (Martins-Costa et al., 2008; Silva et al., 2007).

Dessa maneira, o estabelecimento do intervalo entre pastejos com número de dias fixos pode promover a desfolhação precoce ou tardia do dossel forrageiro, o que pode representar prejuízos à produção, qualidade e eficiência de colheita da forragem (Cândido et al., 2005). Estudos com base no uso da interceptação de luz como forma de controlar e monitorar o processo de pastejo têm demonstrado resultados promissores, pois sugerem que essa técnica pode contribuir para a otimização da produtividade de sistemas de produção animal em pastagens (Carnevalli et al., 2006).
O desenvolvimento de novos genótipos adaptados ao pastejo, associado a estratégias de manejo voltadas para controle da estrutura do dossel e do valor nutritivo do pasto, pode representar uma grande contribuição para o desenvolvimento da pecuária leiteira. Assim, objetivou-se com esse trabalho avaliar o valor nutritivo e a cinética de degradação in vitro de dois genótipos de capim-elefante manejados sob lotação intermitente com duas interceptações luminosas e duas alturas de resíduo pós-pastejo.

\section{MATERIAL E MÉTODOS}

O experimento foi conduzido no campo experimental de Coronel Pacheco, MG, da Embrapa Gado de Leite. O clima da região é do tipo Cwa (mesotérmico) segundo Köppen, e definido como clima tropical chuvoso no verão e com inverno seco entre junho e setembro (Peel et al., 2007). As coordenadas geográficas do local são $21^{\circ} 33^{\prime}$ de latitude Sul e $43^{\circ} 16^{\prime}$ de longitude Oeste e altitude de $435 \mathrm{~m}$.

O solo experimental é classificado como Neossolo Flúvico Tb Distrófico (Sistema..., 2006). O resultado da análise de solo revelou $\mathrm{pH}$ $\left(\mathrm{H}_{2} \mathrm{O}\right)=5,8 ; \mathrm{V}=45 \%$; $\mathrm{P}$ disponível (Mehlich- $\mathrm{I}$ ) $=10,5$ e $\mathrm{K}=77 \mathrm{mg} / \mathrm{dm}^{3} ; \mathrm{Ca}=2,3 ; \mathrm{Mg}=1,0 ; \mathrm{Al}$ $=0,0$ e $\mathrm{SB}=3,5 \mathrm{cmolc} / \mathrm{dm}^{3}$. Devido aos valores encontrados na análise de solo, não foi realizada calagem. A fosfatagem foi realizada com a dose de $100 \mathrm{~kg} / \mathrm{ha}$ de $\mathrm{P}_{2} \mathrm{O}_{5}$, utilizando-se $\mathrm{o}$ superfosfato simples como fonte, aplicado no sulco de plantio. A adubação de cobertura foi realizada dentro da estação chuvosa, após cada pastejo, com as doses de $50 \mathrm{~kg} / \mathrm{ha}$ de $\mathrm{N}$ e de $\mathrm{K}_{2} \mathrm{O}$,e $12,5 \mathrm{~kg} /$ ha de $\mathrm{P}_{2} \mathrm{O}_{5}$, por meio da fórmula $20-05-$ 20 .

O plantio para estabelecimento das forrageiras foi realizado no início do período chuvoso de 2008 (setembro-outubro), com espaçamento entre linhas de $0,80 \mathrm{~m}$. Alguns piquetes foram replantados em setembro-outubro de 2009. Após o estabelecimento, foi realizado um pastejo em dezembro de 2009, para condicionamento do pasto, iniciando-se as análises posteriormente, em janeiro de 2010.

O ensaio correspondeu à avaliação de dois genótipos de capim-elefante, obtidos pelo programa de melhoramento da Embrapa Gado de Leite, que foram manejados sob lotação 
intermitente, ao longo da época chuvosa, com período de ocupação de dois dias para atingir as alturas de resíduo de 30 ou $50 \mathrm{~cm}$ e período de descanso necessário para a interceptação de 90 ou 95\% de interceptação luminosa pelo dossel forrageiro. Utilizou-se a combinação fatorial $(2 \times 2 \times 2)$ de dois genótipos de capim-elefante (BRS Kurumi, de porte baixo, e CNPGL 00-1-3, de porte intermediário), duas interceptações luminosas para interrupção da rebrotação (90 e 95\%) e duas alturas de resíduo pós-pastejo (30 e $50 \mathrm{~cm})$, dispostos num delineamento inteiramente ao acaso, com três repetições.

O rebaixamento do dossel forrageiro até o resíduo preconizado foi realizado via pastejo direto, por novilhas mestiças Holandês x Zebu, com peso médio de $190 \mathrm{~kg}$, mediante a utilização da técnica de mob-grazing (Mislevy et al., 1981), simulando a condição de pastejo com lotação intermitente. As unidades experimentais (piquetes) apresentavam dimensões de 15 x 20m, e o ajuste do número de animais por piquete foi feito de acordo com a necessidade de alcançar a altura residual predeterminada. A massa de forragem colhida antes do pastejo serviu como primeira estimativa do número de animais que foram colocados em cada piquete. Após o pastejo dos piquetes experimentais, os animais foram mantidos em pastos reserva de capim-elefante, até o ciclo de pastejo subsequente. O lote de animais utilizado foi o mais uniforme possível, considerando a idade, o peso e o escore corporal. Apesar desse controle, a cada ciclo de pastejo foi sorteado o grupo de animais para cada tratamento, a fim de evitar possíveis interferências decorrentes das diferenças inerentes a cada animal.

Ao longo do período de pastejo dos piquetes, a altura do pasto foi avaliada, a fim de determinar o momento de retirada dos animais, observandose a altura residual preestabelecida. As medições foram realizadas com régua graduada em centímetros, tomando-se 20 leituras ao acaso em cada piquete. Essas leituras também foram realizadas antes da entrada dos animais no piquete, a fim de caracterizar o pasto ao final do período de descanso (pré-pastejo).

Desde o momento da saída dos animais do piquete e ao longo do período de descanso, foram realizadas avaliações da interceptação luminosa pelo dossel forrageiro, por meio de medições não destrutivas com aparelho analisador de dossel Accupar LP 80 (Decagon Devices, Pullman, WA, USA), realizando 10 leituras ao acaso por piquete. Antes da entrada dos animais no piquete, foram retiradas duas amostras rente ao solo em moldura retangular 1,0 x $0,5 \mathrm{~m}\left(0,5 \mathrm{~m}^{2}\right)$ para cálculo da massa de forragem, com o intuito de ajustar a densidade de lotação necessária para o rebaixamento dos piquetes.

A coleta de amostras do pasto foi realizada rente ao solo, durante o período de verão e o início do outono (janeiro a abril). Uma amostra composta da forragem colhida (todos os ciclos de pastejo dentro da estação chuvosa) foi seca em estufa de ventilação forçada de ar a $55^{\circ} \mathrm{C}$, moída e avaliada quanto a seus teores de matéria seca (MS), proteína bruta (PB), fibra em detergente neutro (FDN), lignina e digestibilidade in vitro da matéria seca (DIVMS), conforme metodologia descrita por Silva e Queiroz (2002).

No Laboratório de Forragicultura do Departamento de Zootecnia da Universidade Federal de Viçosa, foram feitas as análises para obtenção dos teores de fibra em detergente neutro indigestível (FDNi). As amostras $(0,7 \mathrm{~g})$, previamente moídas $(1 \mathrm{~mm})$, foram incubadas em saquinhos de F57 (Ankon) $\left(20 \mathrm{mg} / \mathrm{cm}^{2}\right)$, num período de 288 horas (Huhtanen et al., 1994), no rúmen de um novilho fistulado. Após esse período, os sacos foram retirados, lavados com água corrente até seu clareamento, submetidos à extração com detergente neutro e lavados com água quente e acetona (Sniffen et al., 1992). Após esse tratamento, os sacos foram sequencialmente secos em estufa de ventilação forçada $\left(55^{\circ} \mathrm{C} / 72\right.$ horas) e em estufa não ventilada $\left(105^{\circ} \mathrm{C} / 60\right.$ minutos), sendo em seguida acondicionados em dessecador e pesados.

$\mathrm{O}$ ensaio in vitro de produção de gases foi conduzido no Laboratório de Microbiologia do Rúmen da Embrapa Gado de Leite. No dia anterior ao da inoculação do líquido ruminal, foi adicionado aos frascos $0,3125 \mathrm{~g}$ de amostra moída (1mm) e $28,2 \mathrm{~mL}$ de meio de cultura tamponado, preparado segundo Theodorou et al. (1994), sob fluxo de $\mathrm{CO}_{2}$. Como controle, foram utilizados frascos contendo somente líquido ruminal e meio de cultura (Buffer). Estes foram vedados com rolha de butil e, para evitar contaminação e/ou fermentação antes da adição 
do inóculo ruminal, foram mantidos em geladeira a $4^{\circ} \mathrm{C}$. Cinco horas antes da inoculação com líquido ruminal, eles foram colocados em sala climatizada a $39^{\circ} \mathrm{C}$. Foram necessários 76 frascos (24 amostras, com três repetições por amostra e quatro frascos em branco como controle).

A coleta do líquido ruminal foi realizada manualmente em vaca F1 Holandes x Gir, não lactante, provida de cânula ruminal, mantida a pasto. O líquido ruminal foi transportado para o laboratório em garrafa térmica pré-aquecida com água a $39^{\circ} \mathrm{C}$. No laboratório, o inóculo foi filtrado em dupla camada de gaze, sob fluxo de $\mathrm{CO}_{2}$. Nos frascos contendo amostra e meio de cultura, foram adicionados $3,2 \mathrm{~mL}$ do inóculo (líquido ruminal). Posteriormente, os frascos foram vedados com rolha de butil sobre atmosfera de $\mathrm{CO}_{2}$, lacrados com anilhas de alumínio e deixados em sala climatizada a $39^{\circ} \mathrm{C}$ sob mesa agitadora orbital, Novatecnica, do tipo CT-145. A produção de gases foi mensurada às duas, quatro, seis, nove, 12, 18, 24, 30, 36, 48, 72, 96 horas após a incubação. A leitura do volume de gases foi realizada por meio de aparato de vaso comunicante, de acordo com Fedorah e Hrudey (1983).

A cinética da produção cumulativa de gases foi analisada empregando-se o modelo logístico unicompartimental de Schofield et al. (1994):

$$
\frac{\mathrm{V}(\mathrm{t})=\mathrm{Vf}}{1+\exp \left[2-4^{*} \mathrm{C}^{*}(\mathrm{~T}-\mathrm{L})\right]}
$$

em que:

$\mathrm{V}(\mathrm{t})=$ volume $(\mathrm{mL})$ acumulado no tempo $\mathrm{t}$;

$\mathrm{Vf}=$ total de gás produzido $(\mathrm{mL})$ a partir da fração em questão;

$\mathrm{C}\left(\mathrm{h}^{-1}\right)=$ taxa de degradação;

$\mathrm{L}=$ latência $(\mathrm{h})$;

$\mathrm{T}=$ tempo $(\mathrm{h})$.

Os resultados obtidos foram submetidos à análise de variância, e as médias de tratamentos comparadas pelo teste Tukey, a $5 \%$ de probabilidade. Essas comparações foram executadas no pacote estatístico SAS 9.0, mediante o procedimento LS means (SAS, 2002).

\section{RESULTADOS E DISCUSSÃO}

Não houve efeito $(\mathrm{P}>0,05)$ da interação tripla para nenhuma das variáveis estudadas. Houve efeito da interação genótipos e níveis de interceptação luminosa (IL) para os teores de proteína bruta $(\mathrm{PB})(\mathrm{P}=0,0017)$ (Tab. 1). Não houve efeito de resíduo $(\mathrm{P}=0,211)$, obtendo-se média de $12,5 \%$ de PB. A interceptação luminosa proporcionou respostas diferenciadas dos genótipos, observando-se mais alto teor de PB para BRS Kurumi sob IL de $90 \%$, enquanto para o CNPGL 00-1-3, o maior teor de PB foi com 95\% de IL. O teor de PB do genótipo BRS Kurumi, na interceptação luminosa de 90\% de IL, foi maior do que o encontrado no genótipo CNPGL 00-1-3, no entanto não houve diferença entre os genótipos sob intervalo de desfolhação de $95 \%$ de IL. O maior teor de PB obtido com $90 \%$ de IL é condizente com a menor idade das plantas ao corte (em média, 19 dias para o BRS Kurumi) (Chaves et al., 2013), porém o mais baixo valor observado para o genótipo CNPGL 00-1-3, sob 90\% de IL em relação a 95\% de IL, não é coerente, uma vez que a expectativa é que, principalmente em gramíneas cespitosas, haja redução do valor nutritivo com o prolongamento do intervalo de desfolhação (Candido et al., 2005; Carnevalli et al., 2006). Contudo, para o genótipo CNPGL 00-1-3, parece haver um atraso na emissão de folhas, necessitando, então, de um maior intervalo entre desfolhações (95\% de IL) para que este atinja uma maior produção de folhas, fração de melhor valor nutritivo.

Vale lembrar que, no presente trabalho, os teores de PB correspondem a amostras de planta inteira. Araújo et al. (2011), ao trabalharem com os cinco genótipos de capim-elefante (CNPGL 001-3, CNPGL 94-34-3, BRS Kurumi, CNPGL 92117-3, CNPGL 00-1-5) e o cultivar Mott, em diferentes períodos de descanso $(14,28,42,56$, 70 e 84 dias), encontraram valores de PB semelhantes aos do presente estudo, o que revela o alto valor nutritivo dos genótipos de capimelefante avaliado.

Houve efeito da interação genótipo e níveis de IL para os teores de FDN $(\mathrm{P}=0,044)$ (Tab. 1), assim como efeito de resíduo $(\mathrm{P}=0,046)$. Não foram observadas diferenças nos teores de FDN entre as interceptações luminosas para ambos os genótipos. $\mathrm{O}$ teor de FDN variou entre os genótipos na interceptação luminosa de $90 \%$, observando-se mais altos teores de FDN para o genótipo CNPGL 00-1-3. Não foi observada diferença entre os genótipos na IL de 95\%. 
Tabela 1. Teores de proteína bruta (PB) e de fibra em detergente neutro (FDN) (\% MS) da forragem conforme genótipo e nível de interceptação luminosa (IL) e teores de fibra em detergente neutro indigerível (FDNi) (\% MS) conforme o genótipo e a altura de resíduo pós-pastejo

\begin{tabular}{|c|c|c|c|}
\hline Genótipo & \multicolumn{2}{|c|}{ IL $(\%)$} & EPM \\
\hline & 90 & 95 & \multirow{3}{*}{1,4} \\
\hline & \multicolumn{2}{|c|}{ PB (\%) } & \\
\hline \multirow{3}{*}{$\begin{array}{l}\text { BRS Kurumi } \\
\text { CNPGL 00-1-3 }\end{array}$} & $17,5 \mathrm{Aa}$ & $13,1 \mathrm{bA}$ & \\
\hline & $10,7 \mathrm{Ab}$ & $13,4 \mathrm{aA}$ & \multirow{4}{*}{1,0} \\
\hline & & & \\
\hline BRS Kurumi & $60,4 \mathrm{Ab}$ & $63,2 \mathrm{aA}$ & \\
\hline \multirow[t]{4}{*}{ CNPGL 00-1-3 } & $65,5 \mathrm{Aa}$ & $63,9 \mathrm{aA}$ & \\
\hline & \multicolumn{2}{|c|}{ Resíduo (cm) } & \multirow{5}{*}{0,27} \\
\hline & 30 & 50 & \\
\hline & \multicolumn{2}{|c|}{ FDNi (\%) } & \\
\hline BRS Kurumi & $16,17 \mathrm{Bb}$ & $20,07 \mathrm{aA}$ & \\
\hline CNPGL 00-1-3 & $20,41 \mathrm{Aa}$ & $20,36 \mathrm{aA}$ & \\
\hline
\end{tabular}

a $>$ b compara IL dentro de cada genótipo e $\mathrm{A}>\mathrm{B}$ compara genótipo dentro de cada nível de IL pelo teste Tukey a 5\%. $\mathrm{a}>\mathrm{b}$ compara resíduo dentro de cada genótipo e $\mathrm{A}>\mathrm{B}$ compara genótipo dentro de cada resíduo pelo teste Tukey a 5\%.

Apesar do manejo baseado na IL, a diferença entre os teores de FDN observada entre os genótipos sob IL de $90 \%$ pode ser explicada pela mais rápida rebrotação do genótipo BRS Kurumi (19 dias), com mais rápida emissão de folhas. Realmente, Gomide et al. (2011) encontraram alta taxa de aparecimento e alongamento de folhas para o BRS Kurumi no verão. Outra explicação pode ser a altura residual do pasto. Embora se pretendesse rebaixar o pasto a $30 \mathrm{e}$ $50 \mathrm{~cm}$, nem sempre esse objetivo foi alcançado no genótipo CNPGL 00-1-3, devido a sua forma de crescimento. Assim, na forragem colhida no pré-pastejo, havia uma maior proporção de colmos remanescentes dos ciclos anteriores. Além disso, o maior intervalo de pastejos (Chaves et al., 2013) contribuiu para a redução da relação lâmina/colmo e o aumento do teor de FDN. Os genótipos manejados a $30 \mathrm{~cm}$ obtiveram teor médio de FDN de 62,1\%, enquanto o manejo a $50 \mathrm{~cm}$ proporcionou teor médio de $64,3 \%$.

Os teores de FDN encontrados no presente trabalho foram mais baixos do que os observados por Silva et al. (2002), ao trabalharem com 17 genótipos de capim-elefante, que variaram de 67,6 a $70,6 \%$, provavelmente devido ao manejo com base em dias fixos (36 dias), que fez com que as plantas fossem colhidas mais maduras e, consequentemente, seu valor nutritivo fosse reduzido.
Houve efeito da interação genótipo e resíduo para os teores de fibra em detergente neutro indigestível (FDNi) $(\mathrm{P}=0,032)$, porém não houve efeito de níveis de IL sobre essa variável (Tab. 1). Nota-se que o genótipo BRS Kurumi, no resíduo pós-pastejo de $50 \mathrm{~cm}$, apresentou maior teor de FDNi do que no de $30 \mathrm{~cm}$. Contudo, o genótipo CNPGL 00-1-3 não apresentou diferença nos teores de FDNi em resposta aos resíduos.

Em relação aos genótipos, observa-se que, no resíduo de 30cm, o genótipo CNPGL 00-1-3 apresentou maior teor de FDNi do que o genótipo BRS Kurumi. No entanto, no resíduo de $50 \mathrm{~cm}$, não houve diferença no teor de FDNi nos genótipos estudados. Martins-Costa et al. (2008), ao trabalharem com capim-elefante de porte alto com diferentes idades de corte em dias fixos, obtiveram valores de FDNi variando de 20,64\% (aos 30 dias) a 34,63\% (aos 105 dias).

Não houve efeito dos tratamentos estudados sobre os teores de lignina $(\mathrm{P}>0,05)$, que apresentou teor médio de $4,1 \%$ para genótipos, níveis de IL e resíduos. Voltolini et al. (2008), ao trabalharem com capim-elefante cv. Napier com período de descanso de 37 dias, observaram teores médios de $2,48 \%$ de lignina. Araújo et al. (2011), ao trabalharem com diferentes genótipos de capim-elefante anão, incluindo os dois do presente experimento, observaram aumento nos teores de lignina decorrente da maturidade. Os autores encontraram teores de lignina de 4,2 e 
$5,1 \%$, para o cv. BRS Kurumi, e 4,5 e 4,6\%, para o cv. CNPGL 00-1-3, aos 28 e 42 dias de rebrotação, respectivamente. A maioria das espécies forrageiras apresenta declínio no seu valor nutritivo com o aumento da idade, resultado do decréscimo da relação folha/haste combinada com a crescente lignificação da parede celular (Balsalobre et al., 2003). Nesse aspecto, a mais alta relação lâmina/colmo do capim-elefante anão (BRS Kurumi) favorece a manutenção de melhor valor nutritivo por período de tempo mais prolongado. Dados de relação lâmina/colmo deste estudo foram apresentados por Gomide et al. (2015) e verificou-se que o genótipo BRS Kurumi proporcionou maior relação folha/colmo em relação ao CNPGL 00-1-3 (1,34 vs. 0,96), assim como o resíduo de $30 \mathrm{~cm}$ em relação ao de $50 \mathrm{~cm}$ $(1,25$ vs. 1,04$)$.

Houve efeito das interações genótipo e nível de IL $(\mathrm{P}=0,0075)$ e genótipo e altura de resíduo $(\mathrm{P}=0,0413)$ para os coeficientes de digestibilidade in vitro da matéria seca (DIVMS) (Tab. 2). Observa-se que as interceptações luminosas alteraram a DIVMS dos genótipos. Para BRS Kurumi, o aumento na IL reduziu a DIVMS de 70,5 para $66,8 \%$.

Contudo, o genótipo CNPGL 00-1-3 apresentou maior DIVMS sob $95 \%$ de IL. Isso pode estar relacionado aos teores de $\mathrm{PB}$ que tiveram o mesmo comportamento (Tab. 1).

Tabela 2. Digestibilidade in vitro na MS (\%) da forragem conforme genótipos e interceptação luminosa ao corte e conforme genótipos e altura de resíduo pós-pastejo

\begin{tabular}{|c|c|c|c|}
\hline Genótipo & \multicolumn{2}{|c|}{ IL $(\%)$} & EPM \\
\hline \multirow{5}{*}{$\begin{array}{l}\text { BRS Kurumi } \\
\text { CNPGL 00-1-3 }\end{array}$} & 90 & 95 & \multirow{4}{*}{1,05} \\
\hline & $70,5 \mathrm{Aa}$ & $66,8 \mathrm{bA}$ & \\
\hline & $64,2 \mathrm{Bb}$ & $67,5 \mathrm{aA}$ & \\
\hline & \multicolumn{2}{|c|}{ Resíduo $(\mathrm{cm})$} & \\
\hline & 30 & 50 & \multirow{3}{*}{1,05} \\
\hline BRS Kurumi & $70,9 \mathrm{Aa}$ & $65,9 \mathrm{bA}$ & \\
\hline CNPGL $00-1-3$ & $66,0 \mathrm{Ab}$ & $65,7 \mathrm{aA}$ & \\
\hline
\end{tabular}

a $>$ b compara IL dentro de cada genótipo e A>B compara genótipo dentro de cada nível de IL pelo teste Tukey a 5\%. $\mathrm{a}>\mathrm{b}$ compara resíduo dentro de cada genótipo e $\mathrm{A}>\mathrm{B}$ compara genótipo dentro de cada resíduo pelo teste Tukey a 5\%.

Com o prolongamento do intervalo de desfolhações, há tendência de incremento na participação de colmos que, consequentemente, promove diminuição no teor de $\mathrm{PB}$, aumento nos teores de FDN e FDA e redução na relação lâmina/colmo. No genótipo CNPGL 00-1-3 parecer haver um atraso na emissão de folhas, sendo importante maior intervalo de pastejos para garantir adequada proporção de folhas na forragem. A DIVMS foi maior para o genótipo BRS Kurumi em relação ao genótipo CNPGL 00-1-3, na IL de $90 \%$, entretanto não houve diferença na DIVMS entre os genótipos na interceptação luminosa de 95\%.

Em relação ao resíduo pós-pastejo, o genótipo BRS Kurumi apresentou maior DIVMS no resíduo de $30 \mathrm{~cm}$ do que no resíduo de $50 \mathrm{~cm}$, provavelmente devido ao seu maior teor de $\mathrm{PB}$ e menor teor de FDN. Já o genótipo CNPGL 00-1-
3 não apresentou diferença na DIVMS quanto aos resíduos estudados. O genótipo BRS Kurumi apresentou maior DIVMS no resíduo pós-pastejo de $30 \mathrm{~cm}$ do que o genótipo CNPGL 00-1-3. Contudo, não houve diferença entre os genótipos no resíduo de $50 \mathrm{~cm}$.

Os valores de digestibilidade in vitro da MS observados no presente trabalho são superiores aos obtidos por Lista et al. (2007), ao trabalharem com o cultivar Napier, e por Fernandes et al. (2002), ao trabalharem com o genótipo BRS Kurumi, os quais estudaram intervalo de pastejo fixo, no qual obtiveram valores de 54,2 e $62,8 \%$, respectivamente.

Os valores estimados para os parâmetros da cinética de fermentação ruminal in vitro são apresentados na Tab. 3 . 
Valor nutritivo e cinética...

Tabela 3. Parâmetros cinéticos da fermentação ruminal de genótipos de capim-elefante anão em função das interceptações luminosas e dos resíduos pós-pastejo

\begin{tabular}{cccccc} 
Genótipos & $\begin{array}{c}\text { Interceptação } \\
\text { luminosa }(\%)\end{array}$ & Resíduo $(\mathrm{cm})$ & $\begin{array}{c}\mathrm{Vf} \\
(\mathrm{Ml})\end{array}$ & $\begin{array}{c}\mathrm{c} \\
\left(\mathrm{h}^{-1}\right)\end{array}$ & $\begin{array}{c}\mathrm{L} \\
(\mathrm{h})\end{array}$ \\
\hline \multirow{3}{*}{ BRS Kurumi } & 90 & 30 & 163,5 & 0,0262 & 3,6114 \\
& 90 & 50 & 155,2 & 0,0255 & 3,6846 \\
& 95 & 30 & 167,5 & 0,0257 & 2,3910 \\
& 95 & 50 & 176,3 & 0,0237 & 2,1989 \\
\hline \multirow{5}{*}{ CNPGL 00-1-3 } & 90 & 30 & 170,2 & 0,0215 & 4,5934 \\
& 90 & 50 & 176,0 & 0,0237 & 3,4256 \\
& 95 & 30 & 164,5 & 0,0266 & 3,7123 \\
& 95 & 50 & 164,2 & 0,0224 & 3,3337 \\
\hline
\end{tabular}

$\mathrm{Vf}=$ total de gás produzido a partir da fração em questão, $\mathrm{c}=$ taxa de crescimento específico dos microrganismos sobre a fração e $\mathrm{L}=$ latência.

Os valores estimados para o volume final de gás (Vf) oriundo da degradação da matéria seca (MS) dos materiais incubados foram semelhantes (Tab.3, Fig. 1 e 2), exceto para o genótipo BRS Kurumi, manejado com $50 \mathrm{~cm}$ de resíduo e $90 \%$ de IL, o qual apresentou menor valor de Vf, embora os valores de taxa de degradação $(C)$ e de tempo de latência (L) tenham sido próximos aos observados para o mesmo material manejado com $30 \mathrm{~cm}$ de resíduo. No entanto, observou-se, para o genótipo CNPGL 00-1-3, a menor taxa de degradação e a maior latência, quando manejado a $30 \mathrm{~cm}$ de altura de resíduo, com $90 \%$ de IL, o que, provavelmente, está relacionado ao longo período de descanso obtido para essa combinação (52 dias) e a menor relação lâmina/colmo (Tab. 1).
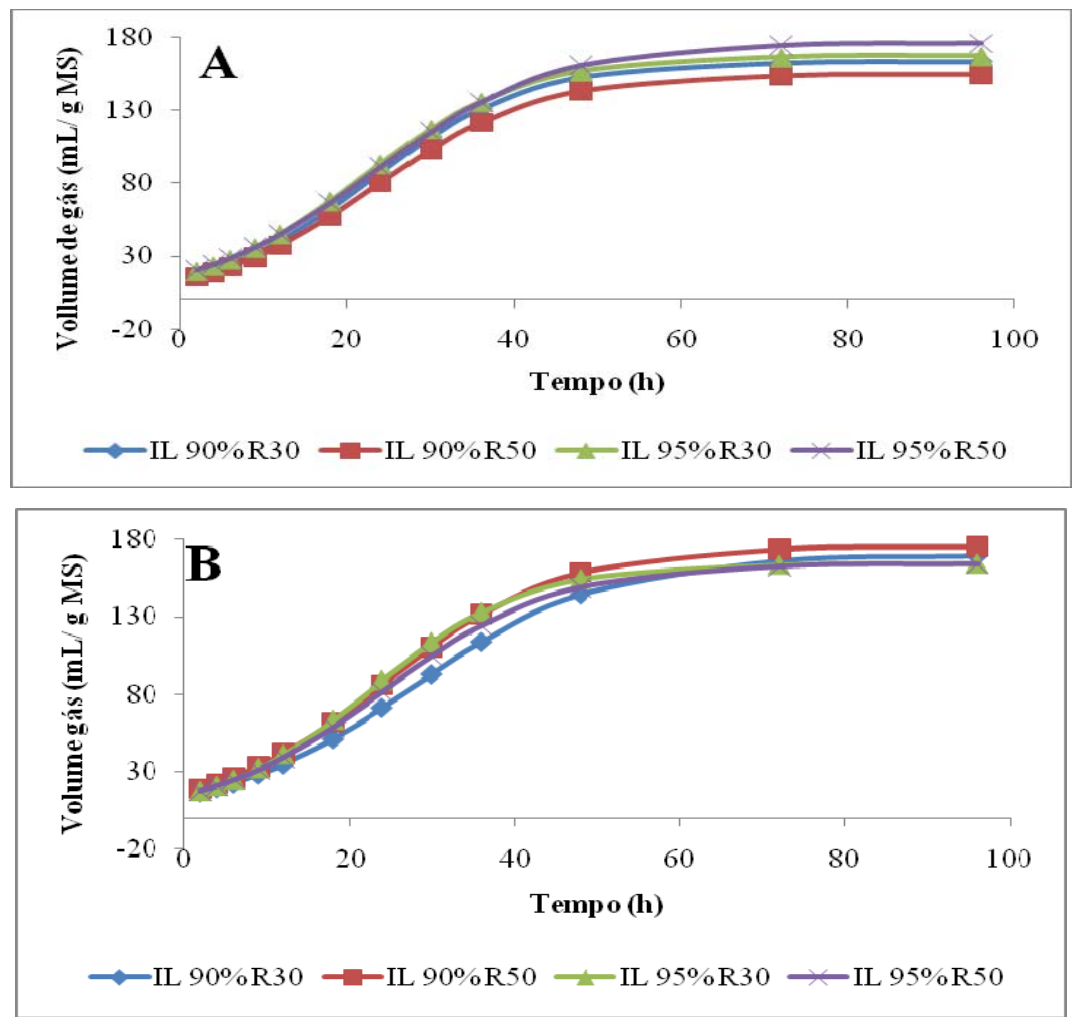

Figura 1. Curva de produção cumulativa de gás para os genótipos BRS Kurumi (A) e CNPGL 00-1-3 (B) de acordo com o manejo empregado. 
Os menores valores de latência (L) foram obtidos para o genótipo BRS Kurumi manejado com 95\% de IL, em ambas as alturas de resíduo, indicando maior facilidade de adesão dos microrganismos a esse substrato.

Segundo Guimarães Júnior et al. (2008), a latência representa o tempo compreendido entre o início da incubação até a ação microbiana sobre a amostra testada. As reduções no tempo de colonização são favorecidas pela presença de substratos prontamente fermentáveis e por características físicas e químicas da parede celular da amostra. No presente trabalho, o menor tempo de colonização foi verificado para o genótipo BRS Kurumi (aproximadamente três horas), com isso essa forrageira apresenta pico inicial mais precoce de produção de gases se comparada ao genótipo CNPGL 00-1-3 (aproximadamente quatro horas). Esse resultado revela que o genótipo BRS Kurumi provavelmente apresenta maiores teores de substratos prontamente fermentáveis, principalmente se for associado ao seu valor nutritivo.

\section{CONCLUSÕES}

Recomenda-se a utilização do genótipo BRS Kurumi manejado a $90 \%$ de IL e com altura de resíduo pós-pastejo de $30 \mathrm{~cm}$, enquanto o CNPGL 00-1-3 deve ser manejado a 95\% de IL, independentemente da altura de resíduo, estratégias que beneficiam o valor nutritivo da forragem.

\section{REFERÊNCIAS}

ARAÚJO, S.A.C.; VASQUEZ, H.M.; SILVA, J.F.C. et al. Produção de matéria seca e composição bromatológica de genótipos de capim-elefante anão. Arch. Zootec., v.60, p.8391, 2011.

BALSALOBRE, M.A.A.; CORSI, M.; SANTOS, P.M. et al. Composição química e fracionamento do nitrogênio e dos carboidratos do capim-tanzânia irrigado sob três níveis de resíduo pós-pastejo. Rev. Bras. Zootec., v.32, p.519-528, 2003.

CÂNDIDO， M.J.D.; GOMIDE， C.A.M.; ALEXANDRINO, E. et al. Morfofisiologia do dossel de Panicum maximum cv Mombaça sob lotação intermitente com três períodos de descanso. Rev. Bras. Zootec., v.34, p.338-347, 2005.
CARNEVALLI, R.A.; SILVA, S.C.; BUENO, A.A.O. et al. Herbage production and grazing losses in Panicum maximum cv. Mombaça under four grazing managements. Trop. Grassl., v.40, p.165-176, 2006.

CHAVES, C.S.; GOMIDE, C.A.M.; RIBEIRO, K.G. et al. Forage production of elephant grass under intermittent stocking. Pesqui. Agropecu. Bras., v.48, p.234-240, 2013.

FEDORAH, P.M.; HRUDEY, S.E. A simple apparatus for measuring gas production by methanogenic cultures in serum bottles. Environ. Technol., v.4, p.425-432, 1983.

FERNANDES, F.D.; PEREIRA, A.V.; LÉDO, F.J.S.; CARVALHO, M.A. Avaliação agronômica de genótipos de capim-elefante no Distrito Federal. Bol. Pesqui. Desenv., n.41, 2002, 15p.

GOMIDE, C.A.M.; CHAVES, C.S.; RIBEIRO, K.G. et al. Structural traits of elephant grass (Pennisetum purpureum schum.) genotypes under rotational stocking strategies. Afr. J. Range Forage Sci., v.32, p.51-57, 2015.

GOMIDE, C.A.M.; PACIULLO, D.S.C.; COSTA, I.A. et al. Morphogenesis of dwarf elephant grass genótipos in response to intensity and frequency of defoliation in dry and rainy seasons. Rev. Bras. Zootec., v.40, p.1445-1451, 2011.

GUIMARÃES JÚNIOR, R.; GONÇALVES, L.C.; MAURÍCIO, R.M. et al. Cinética de fermentação ruminal de silagens de milheto. Arq. Bras. Med. Vet. Zootec., v.60, p.1174-1180, 2008.

HUHTANEN, P.; KAUSTELL, K.; JAAKKOLA, S. The use of internal markers to predict total digestibility and duodenal flow of nutrients in cattle given six different diets. Anim. Feed Sci. Technol., v.48, p.211-227, 1994.

LISTA, F.N.; SILVA, J.F.C.; VÁSQUEZ, H.M. et al. Avaliação nutricional de pastagens de capim-elefante e capim-mombaça sob manejo rotacionado em diferentes períodos de ocupação. Rev. Bras. Zootec., v.36, p.1406-1412, 2007.

MACOON, B.; SOLLENBERGER, L.E.; MOORE, J.E. Defoliation effects on persistence and productivity of four Pennisetum spp. genotypes. Agron. J., v.94, p.541-548, 2002. 
MARTINS-COSTA，R.H.A.; CABRAL，L.S.; BHERING, M. et al. Valor nutritivo do capimelefante obtido em diferentes idades de corte. Rev. Bras. Saúde Prod. Anim., v.9, p.397-406, 2008.

MISLEVY, P.; MOTT, G.O.; MARTIN, F.G. Screening perennial forages by mob-grazing technique. In: INTERNATIONAL GRASSLAND CONGRESS, 14., 1981, Lexington. Proceedings... Boulder: Westview Press, 1981. p.516-519.

PEEL, M.C.; FINLAYSON, B.L.; MCMAHON, T.A. Updated world map of the Köppen-geiger climate classification. Hydrol. Earth Syst. Sci., v.11, p.1633-1644, 2007.

PEREIRA, A.V.; FERREIRA, R.P.; PASSOS, L.P. et al. Variação da qualidade de folhas em cultivares de capim-elefante (Pennisetum purpureum) e híbridos de capim elefante $\mathrm{x}$ milheto ( $P$. purpureum x P. glaucum), em função da idade da planta. Ciênc. Agrotec., v.24, p.490499, 2000.

SAS user guide. Version 9.0. Cary: SAS, 2002.

SCHOFIELD, P.; PITT, R.E.; PELL, A.N. Kinetics of fiber digestion from in vitro gas production. J. Anim. Sci., v.72, p.2980-2991, 1994.

SILVA, D.J.; QUEIROZ, A.C. Análise de alimentos: métodos químicos e biológicos. Viçosa: UFV, 2002. 235p.

SILVA, M.M.P.; VASQUEZ, H.M.; SILVA, J.F.C. et al. Composição bromatológica, disponibilidade de forragem e índice de área foliar de dezessete genótipos de capim-elefante (Pennisetum purpureum Schum.) sob pastejo, em Campos dos Goytacazes, RJ. Rev. Bras. Zootec., v.31, Supl., p.313-320, 2002
SILVA, P.A.; VALADARES FILHO, R.F.D.; VALADARES, P.R. et al. Valor energético do capim-elefante em diferentes idades de rebrota e estimativa da digestibilidade in vivo da fibra em detergente neutro. Arq. Bras. Med. Vet. Zootec., v.59, p.711-718, 2007.

SILVA, S.H.B.; SANTOS, M.V.F.; LIRA, M.A. et al. Uso de descritores morfológicos $\mathrm{e}$ herdabilidade de caracteres em genótipos de capim-elefante de porte baixo. Rev. Bras. Zootec., v.38, p.1451-1459, 2009.

SISTEMA brasileiro de classificação de solos. 2.ed. Rio de Janeiro: EMBRAPA Solos, 2006. $306 \mathrm{p}$.

SNIFFEN, C.J.; O'CONNOR, D.J.; VAN SOEST, P.J. et al. A net carbohydrate and protein system for evaluating cattle diets: carbohydrate and protein availability. J. Anim. Sci., v.70, p.3562-3577, 1992.

THEODOROU, M.K.; WILLIAMS, B.A.; DHANOA, M.S. et al. A simple gas production method using a pressure transducer to determine the fermentation kinetics of ruminal feeds. Anim. Feed Sci. Technol., v.48, p.185-197, 1994.

VAN SOEST, P.J. Symposium on factors influencing the voluntary intake of herbage by ruminants: voluntary intake in relation to chemical composition and digestibility. J. Anim. Sci., v.24, p.834-843, 1965 .

VOLTOLINI, T.V.; SANTOS, A.P.; MARTINEZ, J.C. et al. Metabolizable protein supply according to the NRC (2001) for dairy cows grazing elephant grass. Sci. Agric., v.65, p.130-138, 2008. 